\title{
Flow Boiling Results of HFE-7200 in a Multi-Microchannel Evaporator and Comparison with HFE-7100
}

\author{
Vivian Y.S. Lee ${ }^{1}$, Ali Al-Zaidi ${ }^{1}$, Gary Henderson ${ }^{2}$, Tassos G. Karayiannis ${ }^{1}$ \\ ${ }^{1}$ Department of Mechanical and Aerospace Engineering, Brunel University London \\ Kingston Lane, Uxbridge, Middlesex, London, UK UB8 3PH \\ Vivian.Lee@brunel.ac.uk; Ali.Al-Zaidi@brunel.ac.uk; Tassos.Karayiannis@brunel.ac.uk \\ ${ }^{2}$ TMD Technologies Limited \\ Swallowfield Way, Hayes, Middlesex, London UK UB3 1DQ \\ Gary.Henderson@tmd.co.uk
}

\begin{abstract}
The flow boiling characteristics of HFE-7200, a dielectric refrigerant with a suitable boiling temperature for electronics cooling at atmospheric pressure, is presented in this paper. Experiments were conducted for a mass flux of $200 \mathrm{~kg} / \mathrm{m}^{2} \mathrm{~s}$, wall heat flux in the range of $26.2-156.3 \mathrm{~kW} / \mathrm{m}^{2}$ at a system pressure of 1 bar and inlet subcooling of $5 \mathrm{~K}$. The base area of the multichannel heat sink was $20 \times 20 \mathrm{~mm}$ and consisted of 44 microchannels $360 \mu \mathrm{m}$ wide and $700 \mu \mathrm{m}$ deep $\left(\mathrm{D}_{\mathrm{h}}=475 \mu \mathrm{m}\right)$. High-speed flow visualisation was conducted to study the corresponding two-phase flow pattern development. Bubbly, slug, churn and annular flow were observed in this study. The flow boiling heat transfer coefficient increased with heat flux. The experimental results were compared with results from a similar experimental set-up using HFE-7100 (Heat sink base area $20 \times 25 \mathrm{~mm}, 40$ microchannels of $350 \mu \mathrm{m}$ width and $700 \mu \mathrm{m}$ height, $\left.\mathrm{D}_{\mathrm{h}}=467 \mu \mathrm{m}\right)$. Local heat transfer coefficients of HFE-7100 decreased steadily with increase in vapour quality whilst an increase in heat transfer coefficient was observed near the channel outlet with HFE-7200. Overall both fluids exhibited similar average heat transfer and pressure drop trends across all heat fluxes.
\end{abstract}

Keywords: Flow boiling, Heat transfer, Pressure drop, Microchannels.

\section{Introduction}

High power densities encountered in modern electronics have necessitated the development of effective thermal management solutions for continued enhancement in processing power and device functionality in compact packaging assemblies. The average heat flux in computer chips is increasing and is expected to reach 2 to $4.5 \mathrm{MW} / \mathrm{m}^{2}$ in high performance and desktop computers respectively by 2026 [1]. Local hot spots can be 6-10 times the chip average power [2], giving heat flux values in the range of $12-45 \mathrm{MW} / \mathrm{m}^{2}$. In IGBT modules, the heat flux at the chip level can reach $6.5-50$ $\mathrm{MW} / \mathrm{m}^{2}$ [1]. Embedded-chip cooling using flow boiling in microchannels has emerged as a promising solution to manage high heat fluxes encountered in modern electronics, which have to be maintained below junction temperature ratings of 85$125^{\circ} \mathrm{C}$. Flow boiling can potentially offer better temperature uniformity because of the constant temperature process during saturated flow boiling. Confined by stringent regulations, chemically inert and environmentally-friendly dielectric coolants such as hydrofluoroethers (HFE) are preferred over water in applications where higher design safety factors are required. Pumped two-phase loops require lower coolant inventory, have better equipment reliability compared to miniature vapourcompression cycles [3]-[6], consistent and better system performance compared to single-phase cooling using miniature heat sinks [7] or embedded heat pipes [8] that have also been developed for high heat flux electronics cooling. Nonetheless, poor understanding of the effect of flow boiling instabilities [9] and surface characteristics [10] on heat transfer performance, disagreements in the dominant heat transfer mechanism [1], possible high boiling incipience temperatures in certain cases [11] (where surface characteristics and system design are not well considered) and lack of general design correlations hinder the technological implementation of two-phase microchannel heat sinks for electronics cooling.

In this study, a pumped two-phase loop using fluid HFE-7200, with a boiling point of $76^{\circ} \mathrm{C}$ at $1 \mathrm{bar}$, has been developed for cooling high heat flux devices with an ultimate air-cooled heat sink. The set-up includes a parallel microchannel evaporator and a compact microchannel liquid-to-air condenser. The evaporator has a footprint area of $20 \times 20 \mathrm{~mm}$ with 44 parallel channels of width $360 \mu \mathrm{m}$ and height $700 \mu \mathrm{m}$. Mass flow rate, temperature and pressure drop measurements were 
carried out to investigate the performance of the microchannel evaporator. A high-resolution camera was used to study twophase flow pattern development in the microchannel array.

\section{Experimental Facility}

The experimental facility is illustrated in Fig. 1. The main loop using HFE-7200 has an auxiliary cooling part consisting of a water-glycol chiller. The main loop consists of a reservoir, a gear pump (GJ-N23FF2S from Micropump $\circledast$ ), two Coriolis mass flowmeters for low and high mass flow rates (OPTIMASS 3000 S01 and S03 from Krohne), a pre-heater, test section and an air-cooled condenser. System pressure is regulated using an immersion heater in the reservoir by a PID controller and the water-glycol chiller is used to control the fluid temperature upstream of the pump. A high-speed camera (Phantom Miro Lab110) was coupled with a Huvitz HSZ-645TR microscope for flow visualisation, recorded at $5000 \mathrm{f} / \mathrm{s}$ at a resolution of 512 x 512 pixels for $1.33 \mathrm{~s}$. All instruments were connected to National Instruments Data Acquisition System and monitored through a LabVIEW programme. Data were recorded for a period of $90 \mathrm{~s}$ at a frequency of $1 \mathrm{kHz}$ after steady-state conditions are achieved and the values are averaged for data reduction. Steady state was considered when the temperature, pressure and mass flow rates do not vary significantly over the course of $180 \mathrm{~s}$.

The test section is shown in Fig. 2. It consists of a polycarbonate top plate, cover plate, housing, copper heat sink, cartridge heaters and an aluminium bottom plate. The heat sink was machined from oxygen-free copper and has dimensions $90.0 \mathrm{~mm}(\mathrm{H}) \times 26.2 \mathrm{~mm}(\mathrm{~W})$ x $46.2 \mathrm{~mm}(\mathrm{~L})$, including the plenum. Forty-four parallel microchannels were machined to a square base area of $20 \mathrm{~mm}$ x $20 \mathrm{~mm}$ using a high-precision milling machine (Kern HSPC-2216) with a carbide end-mill of $0.35 \mathrm{~mm}$ diameter at a speed of $18,000 \mathrm{rpm}$ and a feed rate of $300 \mathrm{~mm} / \mathrm{min}$. The channel dimensions were $0.36 \mathrm{~mm}$ wide, $0.7 \mathrm{~mm}$ deep and $20 \mathrm{~mm}$ in length. The corresponding hydraulic diameter was $475 \mu \mathrm{m}$. The average surface roughness was found to be $0.23 \mu \mathrm{m}$, measured with the Zygo NewView 500 surface profiler. Four cartridge heaters of maximum heating power of $200 \mathrm{~W}$ each were inserted vertically at the bottom of the block.

Seventeen K-type thermocouples with accuracies of $\pm 0.2 \mathrm{~K}$ were used to measure the temperature distribution in the block. Five thermocouples, each $3.3 \mathrm{~mm}$ apart, were positioned along the channel and inserted into the heat sink to a depth of $10 \mathrm{~mm}$, i.e. to the centre of the block, and $1.6 \mathrm{~mm}$ from the channel bottom wall to measure axial temperature. From the other side of the heat sink, five thermocouples were inserted at the same coordinates but only to a depth of $5 \mathrm{~mm}$ to measure traverse temperature distribution. Six additional thermocouples in the vertical direction, each $5 \mathrm{~mm}$ apart, were used to measure the heat flux at the base of the heat sink. The inlet/outlet plenum and fluid manifolds are machined in the polycarbonate top plate. The inlet/outlet pressure and differential pressure were measured across the manifold using two

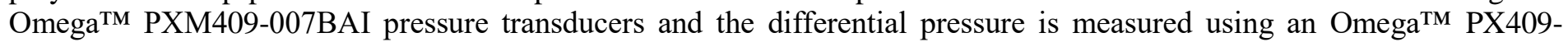
015DWUI. The inlet/outlet fluid temperatures were also measured at these points.

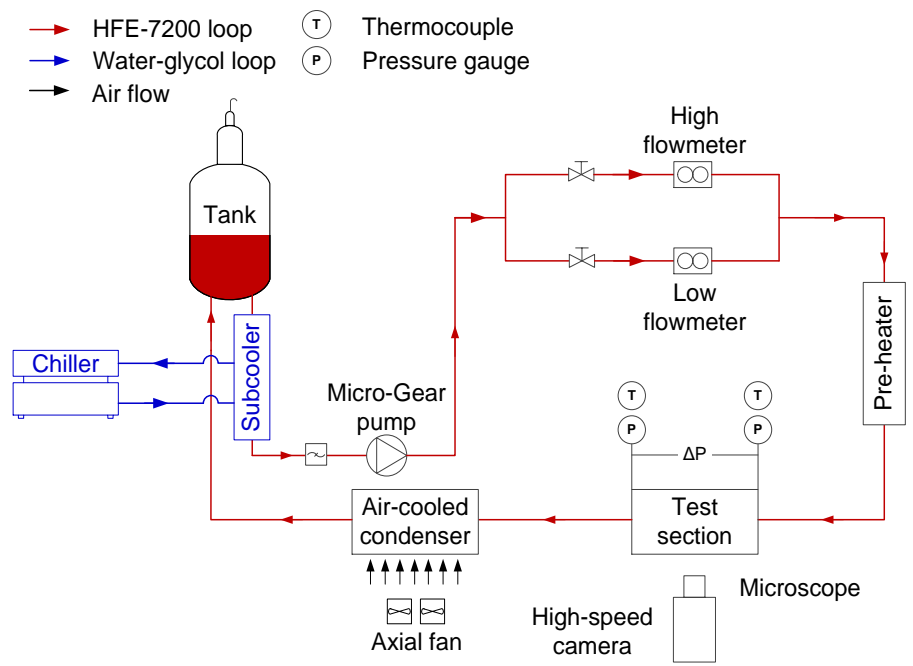

Fig. 1: Schematic diagram of experimental facility.

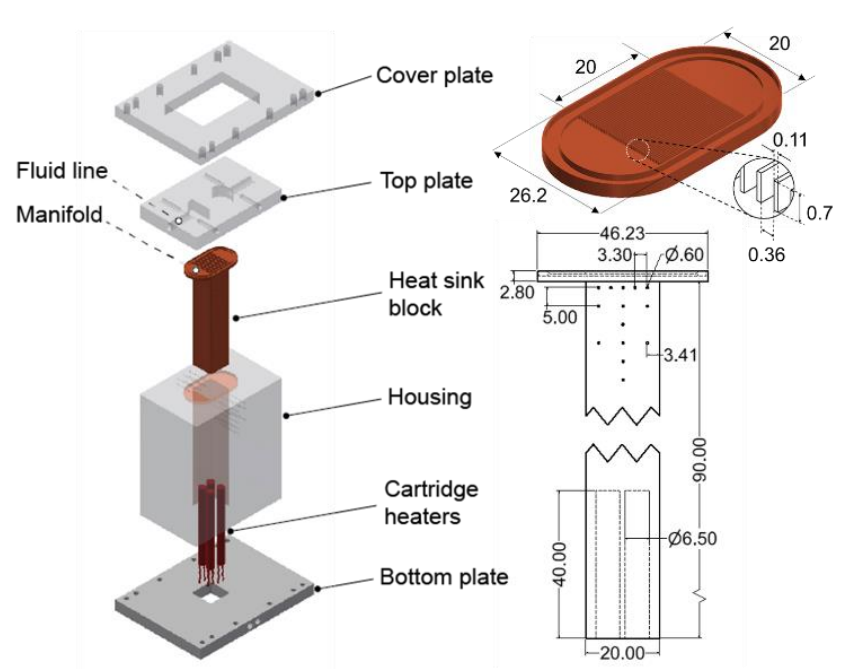

Fig. 2: Test section details, dimensions in $\mathrm{mm}$.

Data from a very similar experimental set-up using HFE-7100 was used in this study [12]. The multichannel evaporator in [12] is of a similar configuration as described above and features a larger base area of $20 \times 25 \mathrm{~mm}$ with 40 
parallel channels of dimensions $350 \mu \mathrm{m}$ width $700 \mu \mathrm{m}$ height $\left(D_{h}=467 \mu \mathrm{m}\right)$. The average surface roughness of the channels is $0.27 \mu \mathrm{m}$.

\section{Data Reduction}

The pressure drop along the microchannel array, $\Delta P_{c h}$, is given by:

$$
\Delta P_{c h}=\Delta P_{\text {total }}-\Delta P_{\text {loss }}
$$

where $\Delta P_{\text {total }}$ is the total measured pressure drop and $\Delta P_{\text {loss }}$, given below, is the total pressure loss in Eq. 2 while $\Delta P_{\text {im }}$, $\Delta P_{o m}, \Delta P_{s c}$ and $\Delta P_{s e}$ are the pressure losses in the inlet manifold, outlet manifold, sudden contraction into the microchannels and sudden expansion from the microchannels respectively.

$$
\Delta P_{\text {loss }}=\Delta P_{i, m}+\Delta P_{s c}+\Delta P_{s e}+\Delta P_{o, m}
$$

The pressure drop components in single-phase flow are estimated based on the method described in [13]. The terms $\rho_{f}$, $\beta, V_{f l}, V_{m}$ and $V_{c h}$ in Eq. 3 - 6 are the liquid density, area ratio and fluid velocity in the fluid line (Fig. 2), manifold and channels respectively. The coefficient of pressure loss through a $90^{\circ}$ bend, $K_{90^{\circ}}$, expansion and contraction in the channels, $K_{e}$ and $K_{c}$, and expansion and contraction in the manifold, $K_{e, m}$ and $K_{c, m}$, are found from [14] based on the area ratio of the manifold and multichannels, which are $1.2,0.27,0.29,0.40$ and 0.66 respectively.

$$
\begin{gathered}
\Delta P_{i, m}=\frac{1}{2} \rho_{f}\left[V_{m}{ }^{2} K_{90^{\circ}}+V_{f l}{ }^{2}\left(1-\beta^{2}-K_{e, m}\right)\right] \\
\Delta P_{o, m}=\frac{1}{2} \rho_{f}\left[V_{m}{ }^{2} K_{90^{\circ}}+V_{f l}{ }^{2}\left(1-\beta^{2}+K_{c, m}\right)\right] \\
\Delta P_{s c}=\frac{1}{2} \rho_{f} V_{c h}{ }^{2}\left(1-\beta^{2}+K_{c}\right) \\
\Delta P_{s e}=\frac{1}{2} \rho_{f} V_{c h}{ }^{2}\left(1-\beta^{2}-K_{e}\right)
\end{gathered}
$$

The experimental fanning friction factor is then found by the relation below:

$$
f=\frac{\Delta P_{c h} D_{h} \rho_{f}}{2 L G_{c h}^{2}}
$$

In two-phase flow experiments, $\Delta P_{o, m}$ and $\Delta P_{s e}$ are calculated based on the two-phase equations in [13].

$$
\Delta P_{o, m, t p}=\frac{1}{2} \rho_{f} x_{e}\left\{V_{m}{ }^{2} K_{90}\left(1+\left(\frac{\rho_{f}}{\rho_{g}}-1\right)\left(1+\frac{2.2}{K_{90^{\circ}}\left(2+\frac{R}{D}\right)}\right)\left(1-x_{e}\right)+x_{e}{ }^{2}\right)+\left(\left(\frac{1}{C_{c}}-1\right)^{2}+\left(1-\frac{1}{\beta^{2}}\right)\right)\left(1+\frac{\rho_{f}}{\rho_{g}}\right)\right\}
$$




$$
\Delta P_{s e, t p}=\frac{1}{2} \rho_{f} V_{c h}{ }^{2}[\beta(1-\beta)]\left[\frac{\left(1-x_{e}\right)^{2}}{(1-\alpha)}+\frac{\rho_{g}}{\rho_{f}} \frac{x_{e}{ }^{2}}{\alpha}\right]
$$

The local heat transfer coefficients, $h_{t p(z)}$, were obtained from thermocouple measurements at five locations along the channel bottom wall at the centre of the microchannel array and calculated with Eq. 10 and 11:

$$
\begin{gathered}
q_{b}^{\prime \prime}=k_{c u} \frac{d T}{d y} \\
h_{t p(z)}=\frac{q_{b}^{\prime \prime} W}{\left(T_{w(z)}-T_{f(z)}\right) * N\left(W_{c h}+2 \eta H_{c h}\right)}
\end{gathered}
$$

where $q_{b}^{\prime \prime}, W, N, W_{c h}, H_{c h}$ and $\eta$ are the base heat flux, base width, number of fins, fin width, fin height and fin efficiency respectively. $q_{b}^{\prime \prime}$ is calculated with the gradient of the vertical thermocouples, $d T$, and $k_{c u}$, the thermal conductivity of copper. $T_{w(z)}$ is the local wall temperature, found from Eq. 12. $Y$ is the distance of the topmost axial thermocouples from the channel bottom wall, $1.6 \mathrm{~mm}$, and $T_{f(z)}$ is the local fluid temperature, found from Eq. 13 if in single-phase flow or evaluated at the local saturation pressure if the corresponding $z$ location is in the flow boiling region. The flow boiling length, $L_{s a t}$, is defined by $L_{s a t}=L_{c h}-L_{s u b}$ where $L_{c h}$ is the channel length. The subcooled length, $L_{s u b}$, is found iteratively from Eq. $14-16$.

$$
\begin{aligned}
& T_{w(z)}=T_{t c(z)}-\frac{q_{b}^{\prime \prime} Y}{k_{c u}} \\
& T_{f(z)}=T_{i}+\frac{q_{b}^{\prime \prime} W z}{\dot{m} c_{p}} \\
& L_{s u b}=\frac{\dot{m} c_{p}\left(T_{s a t(z, s u b)}-T_{i}\right)}{q_{b}^{\prime \prime} W} \\
& P_{\text {sat }(z, s u b)}=P_{i}-\frac{2 f_{s p} G_{c h}{ }^{2} L_{s u b}}{D_{h} \rho_{f}}
\end{aligned}
$$

The friction factor, $f_{s p}$, in Eq. 15 is found using the equation for developing flows given below [14]. The fully-developed Poiseuille number $(f R e)_{f d}$ and constants $K(\infty)$ and $C^{+}$are given in [14] and for the current channels and are 15.46, 0.97 and 0.00029 respectively. The dimensionless subcooled length is determined by $L_{s u b}^{+}=\frac{L_{s u b}}{\operatorname{Re} D_{h}}$ where $\operatorname{Re}=\frac{G_{c h} D_{h}}{\mu_{l}}$.

$$
f_{s p}=\frac{1}{R e}\left\{\frac{3.44}{\sqrt{L_{s u b}^{+}}}+\frac{(f R e)_{f d}+\frac{K(\infty)}{4 L_{s u b}^{+}}-\frac{3.44}{\sqrt{L_{s u b}^{+}}}}{1+\frac{C^{+}}{L_{s u b}^{+}}}\right\}
$$

The average two-phase heat transfer coefficient, $\bar{h}_{t p(z)}$, is calculated based on the flow boiling length as shown in Eq. 17 and is presented as a function of wall heat flux, $q_{w}^{\prime \prime}$ (Eq. 18). 


$$
\begin{aligned}
\bar{h}_{t p(z)} & =\frac{1}{L_{s a t}} \int_{L_{s u b}}^{L} h_{t p(z)} d z \\
q_{w}^{\prime \prime} & =\frac{q_{b}^{\prime \prime}\left(W_{c h}+W_{w}\right)}{\left(W_{c h}+2 H_{c h}\right)}
\end{aligned}
$$

The average single-phase Nusselt number is defined in Eq. 19, where the single-phase heat transfer coefficient, $h_{s p(z)}$, is calculated in the same manner described in Eq. $10-13$ and $k_{f}$ is the liquid thermal conductivity of the fluid.

$$
\overline{N u}=\frac{1}{L_{c h}} \int_{0}^{L_{c h}} \frac{h_{s p(z)} D_{h}}{k_{f}} d z
$$

The vapour quality is determined using the specific enthalpy, $i_{(z)}$, saturated liquid enthalpy, $i_{f(z)}$, and enthalpy of vapourisation, $i_{f g(z)}$, of the fluid, evaluated at the $z$ location or at the exit temperature for the exit vapour quality, $x_{e}$.

$$
x_{(z)}=\frac{i_{(z)}-i_{f(z)}}{i_{f g(z)}}
$$

Two-phase flow experiments were conducted at a system pressure of 1 bar with inlet subcooling of $5 \mathrm{~K}$ and mass flux at $200 \mathrm{~kg} / \mathrm{m}^{2} \mathrm{~s}$. The propagated experimental uncertainties have been evaluated using the method described in [15]. The maximum uncertainty values of channel pressure drop, friction factor, base heat flux, heat transfer coefficient and exit quality for the current experimental range are $0.32 \%, 2.39 \%, 2.82 \%, 10.81 \%$ and $17.00 \%$ respectively.

\section{Results and Discussion}

\subsection{Single-phase results}

Single-phase tests were conducted to validate the experimental set-up. Fig. 3 and 4 show the experimental friction factor and average Nusselt number versus Reynolds number respectively. Established correlations in microchannel laminar flows [14], [16] and [17] were used to validate the experimental results. The figures indicate good agreement between the experimental data and existing correlations and any differences are partly within the experimental uncertainty.

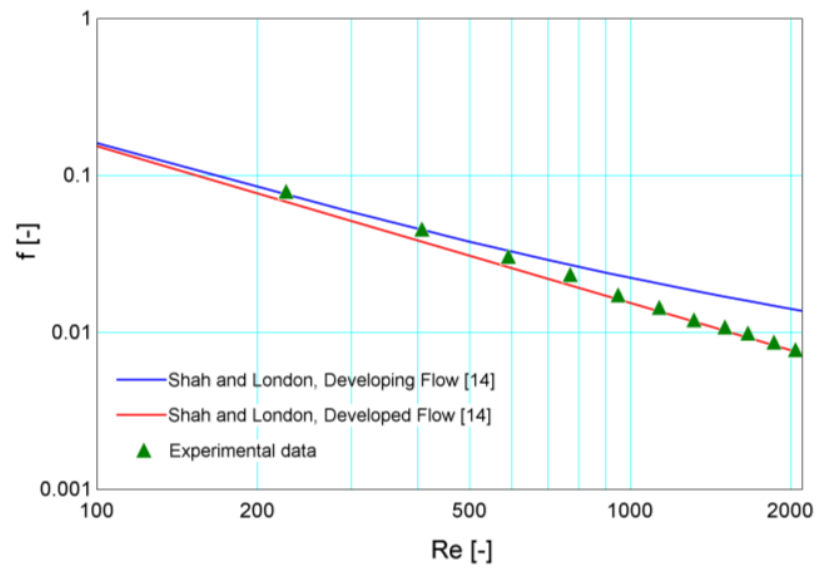

Fig. 3: Single-phase friction factor versus Reynolds number. (Error bars included but not visible in figure.)

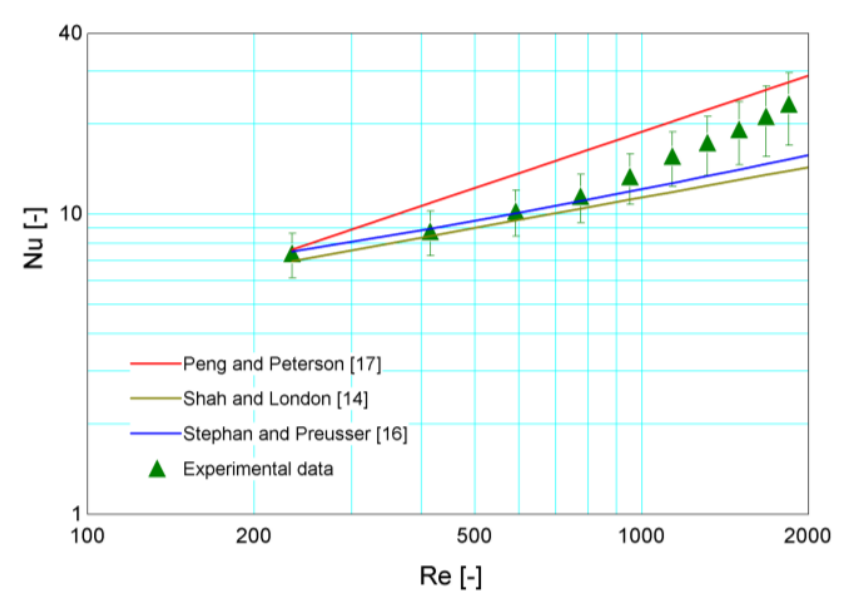

Fig. 4: Average Nusselt number versus Reynolds number. 


\subsection{Two-phase results for HFE-7200 and HFE-7100}

The effect of fluid properties were investigated by comparing flow boiling results using for the two working fluids at similar working conditions. The average surface roughness value and hydraulic diameters of the channels are similar, eliminating the effect of surface roughness and minimising the effect of channel hydraulic diameter on the boiling characteristics. A comparison of fluid properties is shown in Table 1 for HFE-7200 and HFE-7100, evaluated at a pressure of $1 \mathrm{bar}$ and a temperature of $50{ }^{\circ} \mathrm{C}$. The saturation temperature of HFE-7200 is $14.4{ }^{\circ} \mathrm{C}$ higher than that of HFE-7100 at the same operating pressure. The specific heat, liquid density, gas density and gas viscosity of HFE-7200 is $14.6 \%, 5.9 \%, 34.0$ $\%$ and $41.7 \%$ lower than that of HFE-7100. The liquid enthalpy and latent heat of HFE-7200 are both $5.3 \%$ lower than HFE-7100. On the other hand, the surface tension and liquid viscosity values at the same operating pressure is higher in HFE-7200 by $12.7 \%$ and $2.1 \%$ respectively.

The two-phase flow regimes for HFE-7200 were monitored at several locations along the flow direction in the centre of the heat sink. Flow visualisation was conducted near the channel inlet, upstream from the middle of the channel, downstream from the middle and near the channel exit. Bubbly, slug, churn and annular flow were observed. Bubbly flow occurred at low vapour qualities near the inlet and coagulated to form slug flow further downstream, which with increased heat input expanded and covered the entire channel, forcing a transition into annular flow. Alternating churn and annular flow were observed in the channels, especially at moderate to high heat fluxes. At high heat fluxes, alternating churn and annular flow occurred along most of the channel. Similar flow patterns were observed for HFE-7100 [12].

Table 1: Fluid properties at 1 bar and $50^{\circ} \mathrm{C}$.

\begin{tabular}{|c|c|c|c|c|c|c|c|c|}
\hline Fluid & $\begin{array}{c}\text { Saturation } \\
\text { temperature } \\
{\left[{ }^{\circ} \mathrm{C}\right]}\end{array}$ & $\begin{array}{c}\text { Specific } \\
\text { heat } \\
{[\mathrm{J} / \mathrm{kg} \mathrm{K}]}\end{array}$ & $\begin{array}{c}\text { Liquid } \\
\text { enthalpy } \\
{[\mathrm{kJ} / \mathrm{kg}]}\end{array}$ & $\begin{array}{c}\text { Latent } \\
\text { heat } \\
{[\mathrm{kJ} / \mathrm{kg}]}\end{array}$ & $\begin{array}{c}\text { Liquid } \\
\text { density } \\
{\left[\mathrm{kg} / \mathrm{m}^{3}\right]}\end{array}$ & $\begin{array}{c}\text { Surface } \\
\text { tension } \\
{[\mathrm{N} / \mathrm{m}]}\end{array}$ & $\begin{array}{c}\text { Liquid } \\
\text { viscosity } \\
{[\mathrm{kg} / \mathrm{m} \mathrm{s}]}\end{array}$ & $\begin{array}{c}\text { Gas } \\
\text { viscosity } \\
{[\mathrm{kg} / \mathrm{m} \mathrm{s}]}\end{array}$ \\
\hline HFE-7100 & 60.67 & 1178 & 260.737 & 119.985 & 1450 & 0.01054 & 0.000454 & 0.0000192 \\
\hline HFE-7200 & 75.05 & 1006 & 247.033 & 113.634 & 1365 & 0.01188 & 0.000463 & 0.0000112 \\
\hline
\end{tabular}

Fig. 5 depicts the local flow boiling heat transfer coefficient of HFE-7200 with respect to local vapour quality at G=200 $\mathrm{kg} / \mathrm{m}^{2} \mathrm{~s}$ for wall heat fluxes between $26.2-156.3 \mathrm{~kW} / \mathrm{m}^{2}$. The overall trend indicates an increase in local heat transfer coefficient with increase in applied heat flux, especially at low heat flux conditions $\left(26.2-108.7 \mathrm{~kW} / \mathrm{m}^{2}\right)$. The effect of heat flux tends to be less at the higher heat fluxes of these experiments. Local heat transfer coefficients peaked at the inlet of the channels, fluctuated slightly with respect to local vapour quality and increased again near the outlet of the channels. A plausible reason for the high heat transfer coefficients recorded near the channel inlet could be the assumption of a linear pressure drop profile along the channel, as discussed in [18]. The linear assumption could over-predict the local saturation pressure and thus the local saturation temperature. This could have led to a smaller wall superheat term and resulted in an over-prediction of the heat transfer coefficient near the channel inlet. A second possible reason worth considering for further investigation is the possible higher local heat transfer coefficients that can prevail in nucleate boiling. Subsequently, heat transfer coefficients varied only slightly with vapour quality and may be indicative of nucleate boiling in this region. Near the channel exit, an increase in the heat transfer coefficient was observed. The high evaporation rates characteristic of thinfilm evaporation at the liquid-vapour interface in the annular flow regime could explain the rise in heat transfer rate towards the channel exit.

The local flow boiling heat transfer coefficients for HFE-7100 are plotted in Fig. 6 for a similar range of wall heat fluxes at the same mass flux. The local heat transfer coefficients were obtained based on data from three thermocouple locations along the channel bottom wall. The total channel length was $25 \mathrm{~mm}$. The magnitudes of the heat transfer coefficients are close to those observed in HFE-7200, with an initial peak near the channel inlet. The heat transfer coefficients decreased steadily along the channel without an increase towards the exit, contrary the trends observed in Fig. 5. However this lack of increase may be due to the limited number of thermocouples and hence the smaller number of measuring points for the local heat transfer coefficient and needs to be considered further.

The average heat transfer coefficient of both fluids are depicted in Fig. 7. The heat transfer rate increase at a similar gradient in both fluids with increase in wall heat flux. This is consistent with the fluid properties discussed in Table 1, where 
the liquid enthalpy and latent heat deviated only by around $5 \%$ between the fluids. The average heat transfer rate in HFE7200 was slightly higher than HFE-7100, especially at low to moderate heat fluxes.

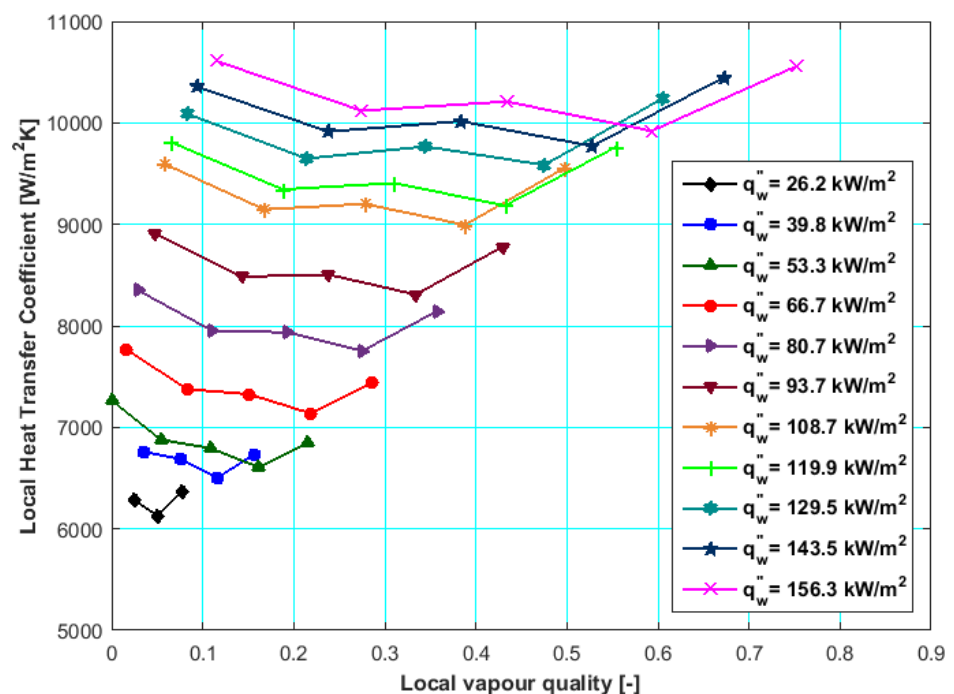

Fig. 5: Effect of heat flux in HFE-7200 at inlet sub-cooling of $5 \mathrm{~K}$ and $\mathrm{G}=200 \mathrm{~kg} / \mathrm{m}^{2} \mathrm{~s}$.

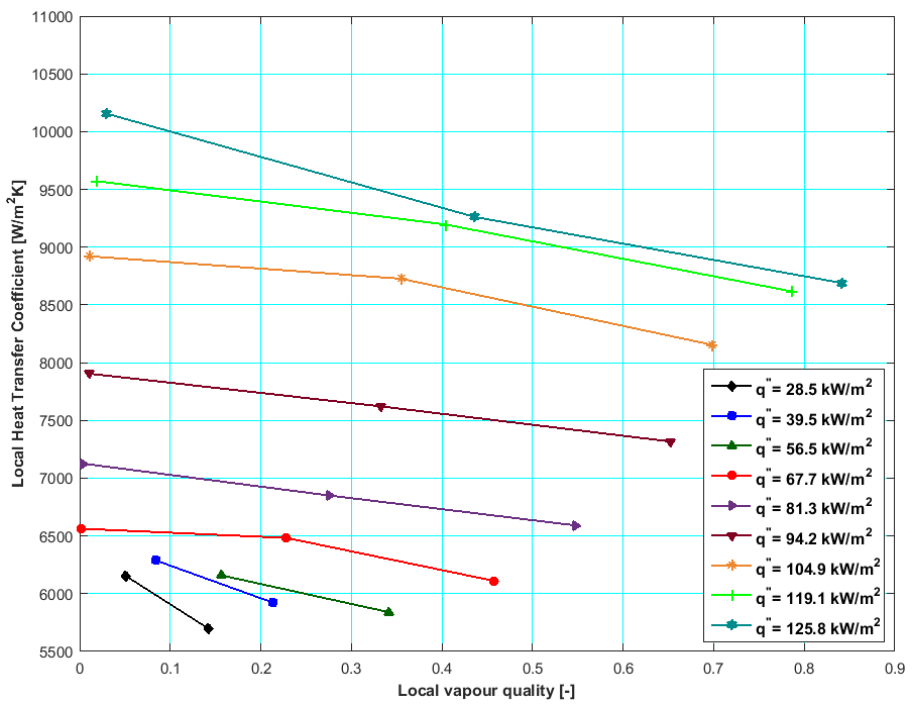

Fig. 6: Effect of heat flux in HFE-7100 at inlet sub-cooling of $5 \mathrm{~K}$ and $\mathrm{G}=200 \mathrm{~kg} / \mathrm{m}^{2} \mathrm{~s}$.

Fig. 8 shows the two-phase pressure drop results plotted against the exit vapour quality for $\mathrm{G}=200 \mathrm{~kg} / \mathrm{m}^{2} \mathrm{~s}$. Pressure drop increased with increase in applied heat flux. The pressure drop of HFE-7200 is close to that of HFE-7100 up until an exit quality of 0.6. Afterwards, the pressure drop of HFE-7100 rises steeply and deviates significantly from HFE-7200. The total two-phase pressure drop in the microchannels consist of frictional pressure drop and acceleration pressure drop [13]. The flow velocity in the gas phase increases as void fraction increases in the channel while the liquid phase velocity decreases. The resulting interfacial shear stress increases, possibly creating a greater frictional pressure drop in the channels. Similarly, acceleration pressure drop increases with an increase in void fraction and exit quality in the channel due to density variation of the liquid and gas phase during phase change. In this case, the liquid density of the fluids differ by only around $6 \%$ and appear not to have a significant influence of the pressure drop difference. While the liquid viscosity of the two fluids is also very similar, the gas viscosity of HFE-7200 is over $40 \%$ lower than that of HFE-7100. The lower flow resistance posed by the gas phase in HFE-7200, especially approaching saturated vapour flow might have contributed to lower the pressure drop across the channel at high exit qualities. 


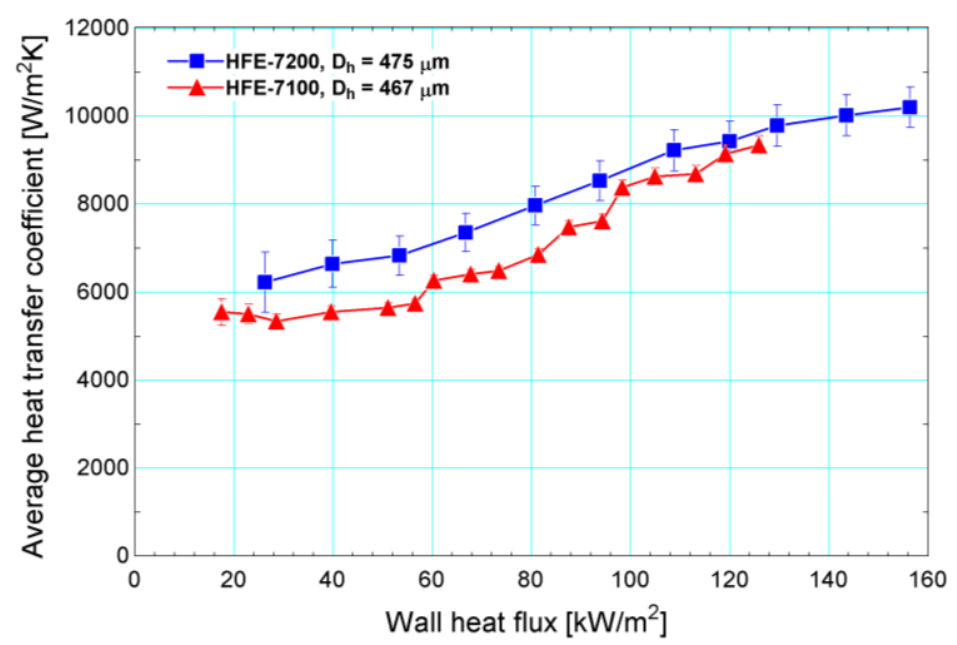

Fig. 7: Average heat transfer coefficient of both fluids as a function of wall heat flux.

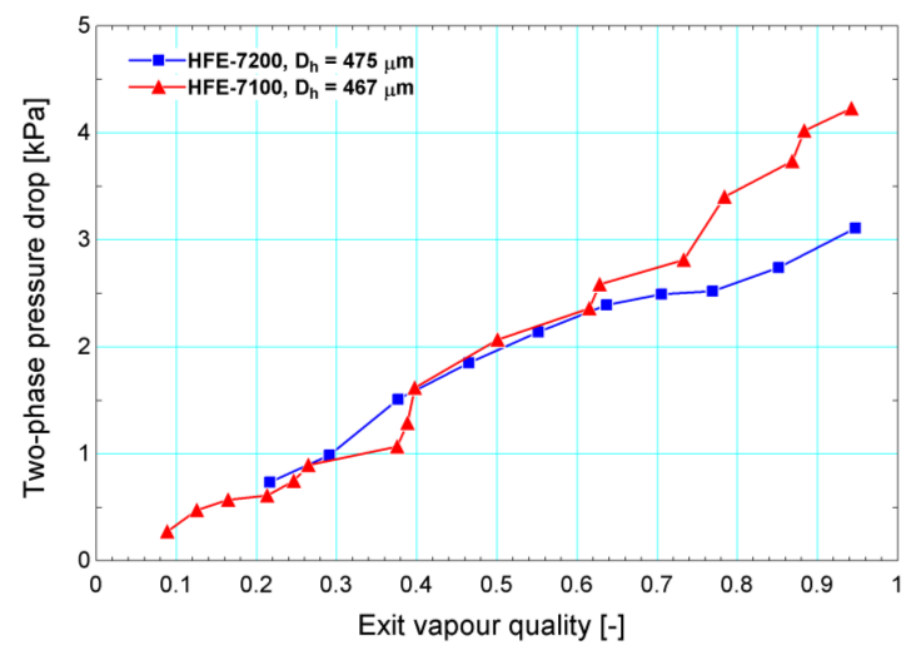

Fig. 8: Two-phase pressure drop of both fluids with respect to exit vapour quality. (Error bars included but not visible.)

\section{Conclusions}

Flow boiling experiments were conducted in a multi-microchannel copper evaporator of base area $20 \mathrm{~mm} \times 20 \mathrm{~mm}$ and hydraulic diameter of $475 \mu \mathrm{m}$ at a system pressure of 1 bar using fluid HFE-7200. Heat transfer and pressure drop results are presented for a mass flux of $200 \mathrm{~kg} / \mathrm{m}^{2} \mathrm{~s}$ with inlet subcooling of $5 \mathrm{~K}$ and wall heat fluxes between $26.2-$ $156.3 \mathrm{~kW} / \mathrm{m}^{2}$. The experimental results are compared with a similar set-up using working fluid HFE-7100. The flow patterns observed in the channels included bubbly flow, slug, churn and annular flow. Local heat transfer trends in HFE7200 decreased with vapour quality but increased near the channel outlet where annular flow is observed. The local heat transfer coefficients also increased with increase in heat flux, with the effect of heat flux diminishing at high heat fluxes. Similar flow patterns and heat flux effect were observed in HFE-7100. The local heat transfer coefficients decreased along the channel and further investigation with more detailed measurements along the channel and evaluation of the flow regimes and fluid properties are required to explain the difference in trends observed near the channel exit, i.e. no increase with quality observed with HFE7100. The average heat transfer coefficient of HFE-7200 is comparable to that of HFE-7100 and increased with increase in wall heat flux. The pressure drop of HFE-7200 is close to that of HFE-7100 but diverges and becomes significantly lower than HFE-7100 at high vapour qualities. This is potentially due to the lower frictional pressure loss, which was related to the large difference in gas viscosity of the two fluids.

\section{Acknowledgements}

The first author would like to thank TMD Technologies Ltd. for their financial support of the research project.

\section{References}

[1] T. G. Karayiannis and M. M. Mahmoud, "Flow boiling in microchannels: Fundamentals and applications," Appl. Therm. Eng., vol. 115, pp. 1372-1397, 2017.

[2] C. Bachmann and A. Bar-Cohen, "Hotspot remediation with anisotropic thermal interface materials," in 2008 11th IEEE Intersoc. Conf. Therm. Thermomechanical Phenom. Electron. Syst. I-THERM, pp. 238-247, 2008.

[3] P. E. Phelan, V. A. Chiriac, and T. Y. Tom Lee, "Current and future miniature refrigeration cooling technologies for high power microelectronics," in IEEE Transactions on Components and Packaging Technologies, vol. 25, no. 3, pp. 356-365, 2002.

[4] A. Heydari, "Miniature vapor compression refrigeration systems for active cooling of high performance computers," in Therm. Thermomechanical Phenom. Electron. Syst. 2002. ITHERM 2002. Eighth Intersoc. Conf., pp. 371-378, 2002.

[5] R. Mongia et al., "Small scale refrigeration system for electronics cooling within a notebook computer," in Thermomechanical Phenom. Electron. Syst. -Proceedings Intersoc. Conf., pp. 751-758, 2006. 
[6] S. Mancin, C. Zilio, G. Righetti, and L. Rossetto, "Mini Vapor Cycle System for high density electronic cooling applications," Int. J. Refrig., vol. 36, no. 4, pp. 1191-1202, 2013.

[7] H. Y. Zhang, D. Pinjala, T. N. Wong, K. C. Toh, and Y. K. Joshi, "Single-phase liquid cooled microchannel heat sink for electronic packages," Appl. Therm. Eng., vol. 25, no. 10, pp. 1472-1487, 2005.

[8] R. J. McGlen, R. Jachuck, and S. Lin, "Integrated thermal management techniques for high power electronic devices," Appl. Therm. Eng., vol. 24, no. 8-9, pp. 1143-1156, 2004.

[9] Y. K. Prajapati, M. Pathak, and M. Kaleem, "Bubble dynamics and flow boiling characteristics in three different microchannel configurations," Int. J. Therm. Sci., vol. 112, pp. 371-382, 2017.

[10] P. Rosa, T. G. Karayiannis, and M. W. Collins, "Single-phase heat transfer in microchannels: The importance of scaling effects," Applied Thermal Engineering, vol. 29, no. 17-18. Pergamon, pp. 3447-3468, 2009.

[11] T.-H. Yen, N. Kasagi, and Y. Suzuki, "Forced convective boiling heat transfer in microtubes at low mass and heat fluxes," Int. J. Multiph. Flow, vol. 29, no. 12, pp. 1771-1792, 2003.

[12] A. H. Al-Zaidi, M. M. Mahmoud, and T. G. Karayiannis, "Flow Boiling in Microchannels With HFE-7100: Experimental Results and Comparision With," in Proceedings of the 16th International Heat Transfer Conference, August 10-15, pp. 1-8, 2018.

[13] John G. Collier and John R. Thome, Convective Boiling and Condensation, $3^{\text {rd }}$ Ed. Clarendon Press, 1996.

[14] R. K. Shah and A. L. London, Laminar Flow Forced Convection in Ducts: A Source Book for Compact Heat Exchanger Analytical Data, 1st ed. Academic Press, 1978.

[15] Hugh W., Coleman, W. Glenn, Steele, Experimentation, Validation, and Uncertainty Analysis for Engineers, 3rd Edition. John Wiley \& Sons, 2009.

[16] K. Stephan, P. Preusser, "Wärmeübergang Und Maximale Wärmstromichte Beim Behältersieden Binärer Und Ternärer Flüssigkeitsgemische," Chem. Ing. Tech., vol. 51, no. 37, 1979.

[17] X. F. Peng and G. P. Peterson, "Convective heat transfer and flow friction for water flow in microchannel structures," Int. J. Heat Mass Transf., vol. 39, no. 12, pp. 2599-2608, 1996.

[18] M. M. Mahmoud and T. G. Karayiannis, "Heat transfer correlation for flow boiling in small to micro tubes," Int. J. Heat Mass Transf., vol. 66, pp. 553-574, 2013. 


\section{Nomenclature}

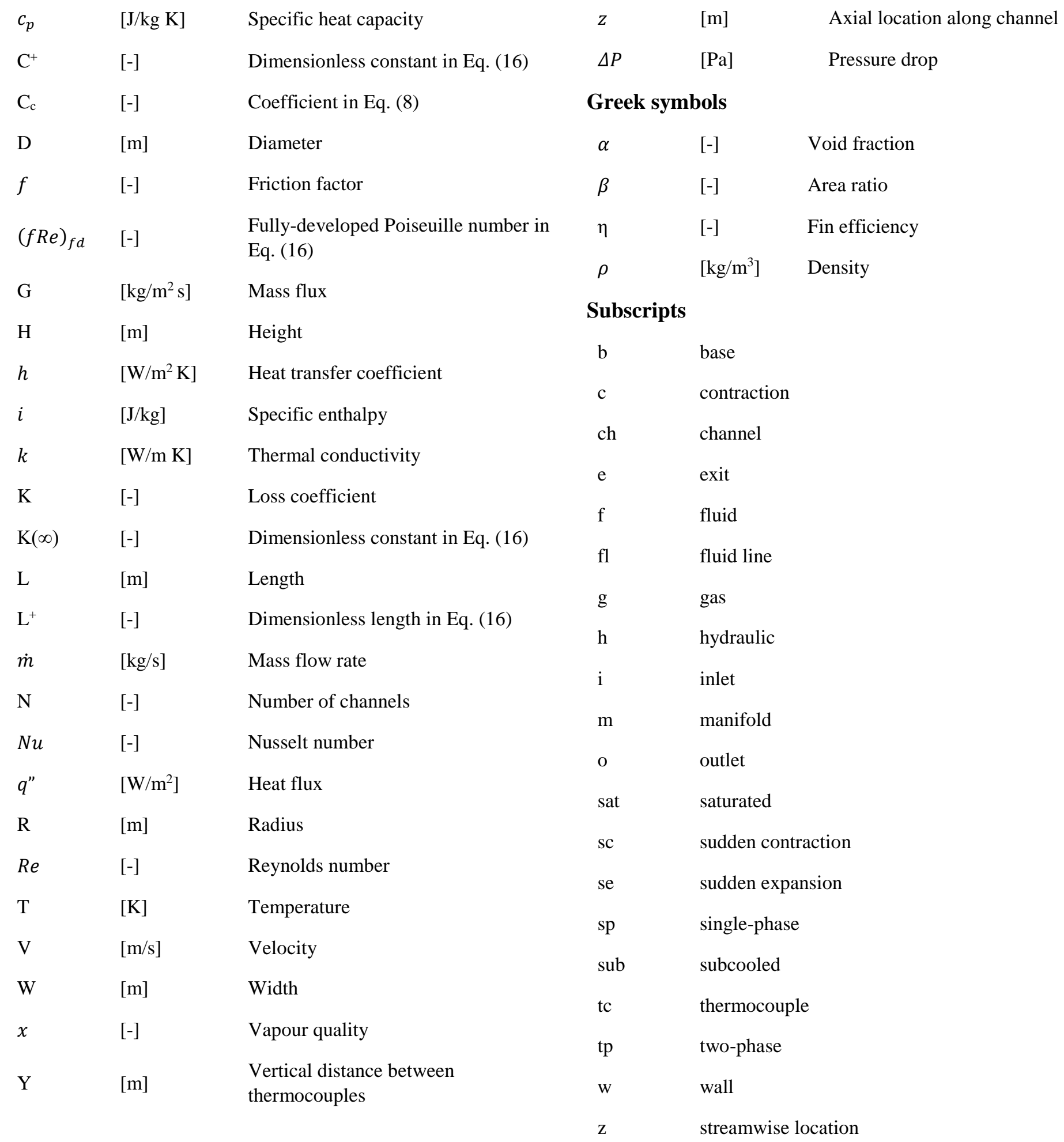

